\title{
Integrative Risk Assessment of Endocrine Disruptors in Switzerland
}

\author{
René Gälli and Christian Braun
}

\begin{abstract}
The objective of the project was to develop an environmental fate model for various substances with endocrine-disrupting potential for the Glattal/Greifensee region in Switzerland and to assess the concentration levels. The model provides an estimate of environmental concentrations based on mass flow calculations from the source of the emissions to the final fate in the environmental compartments. Based on the chemical properties of 20 substances studied in the NRP50 program, the estimated quantities of the substances used and their respective applications, the model predicts mass flows on a local level. Taking into account the respective water flows, these mass flows result in predicted environmental concentrations in surface water and groundwater. These concentrations can be interpreted as averaged levels with geographical resolution in the local scenario. The estrogenic equivalent concentration was assessed by estrogenic equivalence factor-weighted addition of the individual substance concentrations for four different toxicological endpoints. From the 20 substances modelled in this project only a few substantially contribute to the overall endocrine disruption potential. For three of the endpoints used the steroid hormones dominate the endocrine potential. Only the application of the yeast estrogen system (YES) assay predicts a dominant endocrine potential for the degradation products of nonylphenol-poly-ethoxylates (NPnEO) in the year 2004, which was expected to decrease significantly in the year 2007 due to new legislation (almost complete application ban of NPnEO-based detergents as of August 2006). On the basis of the model's geographical resolution it is possible to identify 'hot spots' in terms of high endocrine-disruption potential in the modelled region. For the densely populated and industrialised Glattal/Greifensee region sewage treatment plants discharging into relatively small receiving water systems show the highest endocrine disruption potential (estradiol equivalence concentration of up to $2 \mathrm{ng} / \mathrm{l}$ for the vitellogenin synthesis induction endpoint). In addition to modelling the status quo with respect to endocrine disruption possible future risk reduction measures have been assessed for one identified hot-spot. Whereas an increase in sludge retention time in the existing STP had a moderate effect on the overall endocrine potential, an additional ozonation step showed significant reduction for most endocrinedisrupting substances.
\end{abstract}

Keywords: Endocrine disruption · Local emissions · Mass flow modelling · Surface water

${ }^{\star}$ Correspondence: Dr. R. Gälli

BMG Engineering AG

Ifangstrasse 11

$\mathrm{CH}-8952$ Schlieren

Tel.: +41447329287

Fax: +4144732 6622

E-mail: rene.gaelli@bmgeng.ch

\section{Introduction}

Due to improvements in chemical analytics and the resulting lower quantification limits for micropollutants a large number of chemicals have been found in wastewater, surface waters and groundwater. Among the micropollutants detected are pesticides, biocides, pharmaceuticals, natural hormones and chemicals from various household applications.[1] Trace chemicals in the environment can show adverse health effects, such as endocrine effects on aquatic organisms. Predictive models can be used to predict the local environmental concentrations of these chemicals and, hence, are valuable tools for risk assessments and risk management. Today's standardized models such as the 'European Union System for the Evaluation of Substances' EUSES ${ }^{2]}$ take this approach. However, these models predict average concentrations for an entire region.
In particular chemicals such as endocrine disruptors which exhibit low-dose effects demand risk assessment tools that are based on predicted environmental concentrations estimated for realistic local geographical and demographical situations.

Thus, the development of multimedia movement and fate models goes towards real geographical situations, such as the geography-referenced regional exposure assessment tool GREATER. [3] This model however is focused on the system 'sewer sewage treatment plant (STP) - river' and unlike EUSES cannot simulate different emission scenarios and does not track the final fate including transport of chemicals into environmental compartments other than rivers. It is recognized that metabolites formed during biological degradation should be included in risk assessment approaches. ${ }^{[4]}$ Lately, multi-species models (Level IV) have been proposed by different authors ${ }^{[5,6]}$ but are not used on a routine ba- 
sis in standard risk assessment procedures for the industry so far.

\section{Objectives}

The objective of this project was to develop a predictive model for concentrations of a wide range of substances with endocrine-disrupting potential. A model for the Glattal/Greifensee region capable of assessing the risks associated with nonylphenol polyethoxylates and their degradation products which had been developed during an earlier stage of NRP50[7] was further developed.

\section{Material and Methods}

\section{Model Structure and Capabilities}

The model is set up as a geographical region that is divided into sub-regions defined by the catchment area of the respective sewage treatment plant (STP). The model calculation starts by distributing the emissions between the five environmental compartments air, wastewater treatment, surface water, soil/groundwater, and solid wastes (Fig. 1). The model processes and visualizes mass flows at various levels of detail (e.g. region, district, STP, activated sludge reactor, biodegradation processes). This provides insight into possible hot spots with high endocrine potency, and in turn, may lead to ideas for further measures which had not previously been considered as a result of the information gained about the concentrations within the individual compartments.

\section{Characterization of the Region Glattal/Greifensee}

The region Glattal/Greifensee, located near Zurich, Switzerland, was chosen for its good availability of data, the dense population and the high rate of industrialization, leading to high emissions. Since the receiving waters upstream of Lake Greifensee are small and the river Glatt is only medium-sized, rather high concentrations of pollutants are expected. Furthermore, this region has a set of wastewater treatment plants ranging from very small and basic (ARA Glattfelden/Rheinsfelden, population equivalent of 1'250) to relatively large plants with state-of-the-art equipment (ARA Dübendorf, ARA Uster, population equivalent of $>50$ '000). All this made the region a good test case for the validation of the model.

Data on geography and hydrology was taken from public sources, e.g. Bundesamt für Statistik and Statistisches Amt Kt. ZH (population, agriculture, industry). The modelled region with the network of surface waters is shown in Fig. 2. Data on the

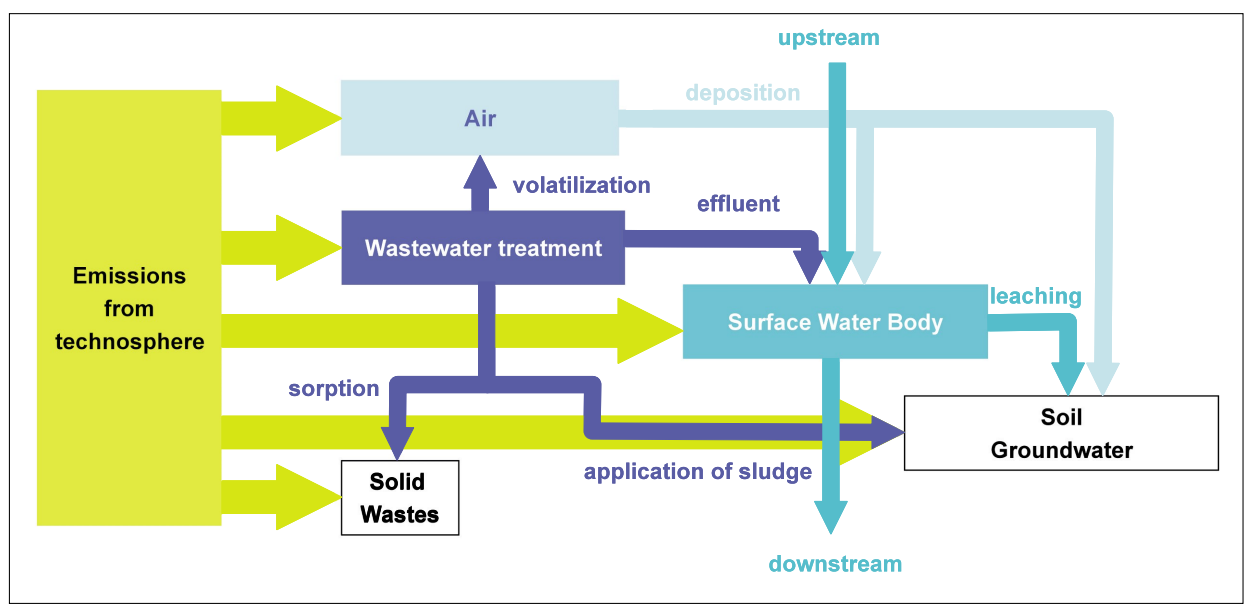

Fig. 1. Mass flow scheme of substances for each catchment area (STP) in the model for the most relevant pathways. Transfer and degradation/formation is calculated inside the compartments (boxes).

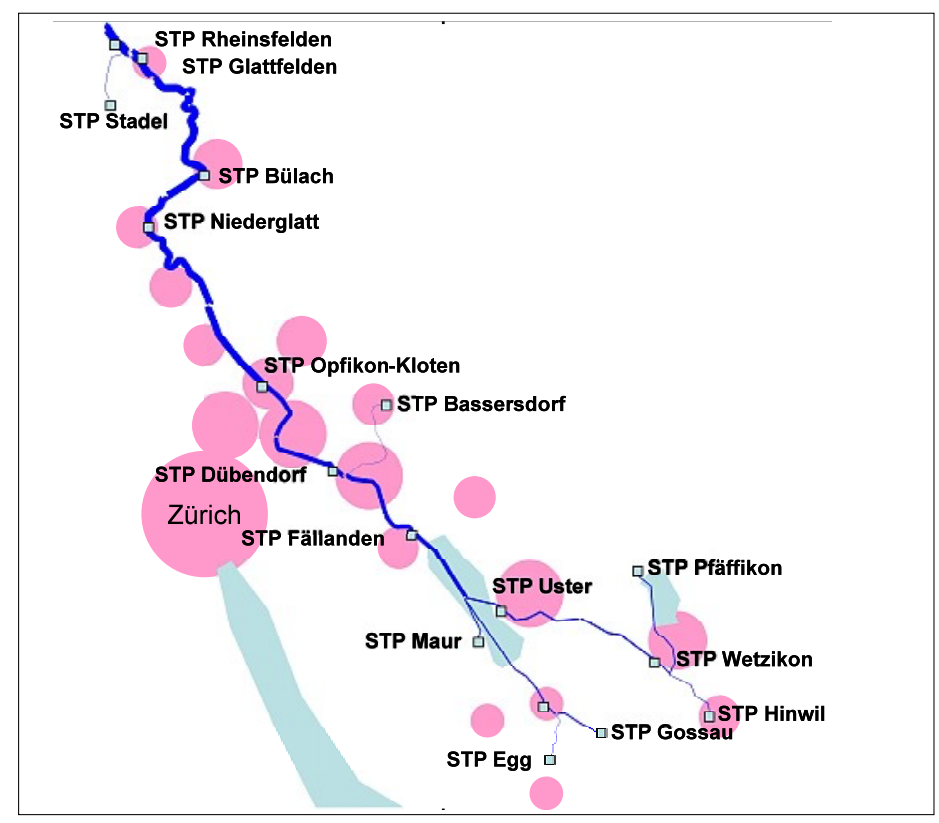

Fig. 2. Geographical representation of the Glatt/Greifensee catchment area. The blue line shows the magnitude of surface water flows in the region (maximum is $8.64 \mathrm{~m}^{3} / \mathrm{s}$ in river Glatt before entering the river Rhine). Boxes represent the 17 STP catchments in the region.

17 STPs was supplied by the environmental authorities (AWEL, Kt. Zürich). Data include estimations of removal efficiency for characteristic parameters (BSB5, CSB, NH4-N, and P).

\section{Movement and Fate of Chemicals}

Based on the chemical properties of the substances, the estimated quantities used, and the applications, the model predicts the movement and fate of the chemicals based on mass flows on a local level. All the necessary calculations (degradation of parent compounds and formation of metabolites, sorption, volatilization, etc.) are performed for the five compartments, resulting in new mass flows to the connected compartments or to the model's boundaries (sediment, soil, solid wastes). The mass flows in surface water are passed on to the next catchment area.
Finally, the concentration in each surface water body is calculated from the initial level of pollution upstream, the calculated mass added in the catchment area, and the average water flow for the section. These concentrations can be interpreted as average levels with geographical resolution in the local scenario.

Modelling the fate of organic compounds in the environment has at least two levels of complexity: (a) the degradation (mineralization) of substances in different compartments (STP, surface water, soil) and (b) the formation of toxic metabolites due to the degradation of substances.

For instance, the degradation of atrazine leads to formation of the toxic metabolite desethyl-atrazine that is subsequently degraded in the environment. A more complex example is the formation of degrada- 
tion products such as nonylphenol from nonylphenolethoxylate: in our model this transformation involves six degradation constants for each environmental compartment and six fractions of formation.

\section{Chemicals Included in the Model}

The model contains data on 20 substances:

Steroidhormones: $17 \beta$-estradiol(E2), estrone (E1), estriol (E3), 17 $\alpha$-ethynylestradiol (EE2)

Pesticides: atrazine and desetyhlatrazine

Plastics monomer: bisphenol A (BPA)

Polybrominated flame retardants $(P B D E)$ : decaBDE, octaBDE, pentaBDE, tetrabromobisphenol A

$U V$ filters: 4-methylbenzylidene camphor (4-MBC), benzophenone-3 (BP-3), ethyhexyl methoxycinnamate (EHMC)

Detergents: nonylphenol polyethoxylate (NPnEO) with its degradation products nonylphenol-di-ethoxylate (NP2EO), nonylphenol-di-carboxylate (NP2EC), nonylphenolethoxylate (NP1EO), nonylphenolcarboxylate (NP1EC), and nonylphenol (NP)

The physicochemical and eco-toxicity data was either taken from literature or calculated with the help of estimation programs. ${ }^{[8]}$ Where applicable, i.e. where sufficient data was available, harmonized values were used. ${ }^{[9]}$ The data was revised by members of other NRP50 projects.

Emission data was deduced from industry sources (e.g. amount produced or processed), literature, and in cooperation with other NRP50 projects. Transfer coefficients (fraction of emissions entering a specific compartment) were taken either from literature (e.g. risk assessment for BPA, ${ }^{[10]}$ studies on atrazine, ${ }^{[11]}$ cooperation partners (PBDEs:[12]), or were estimated due to the simplicity of the potential pathways, e.g. steroid hormones are always discharged into the sewer system.

The local emissions are calculated from the Swiss grand total consumption per substance and year multiplied either by the population share in the STP catchment area ('per capita' - substances like steroid hormones) or by industrial share (e.g. NPnEO) or by the share of agricultural land in the STP catchment area (atrazine). The local emission value is multiplied with the transfer coefficient for the respective compartment, which leads to local environmental emissions to air, wastewater, surface water, soil, and solid waste of the substance.

\section{Estrogenic Equivalent Concentration (EEQ)}

The EEQ can be assessed by estrogen equivalence factor-weighted addition of the calculated individual substance concentrations. From the concentrations in

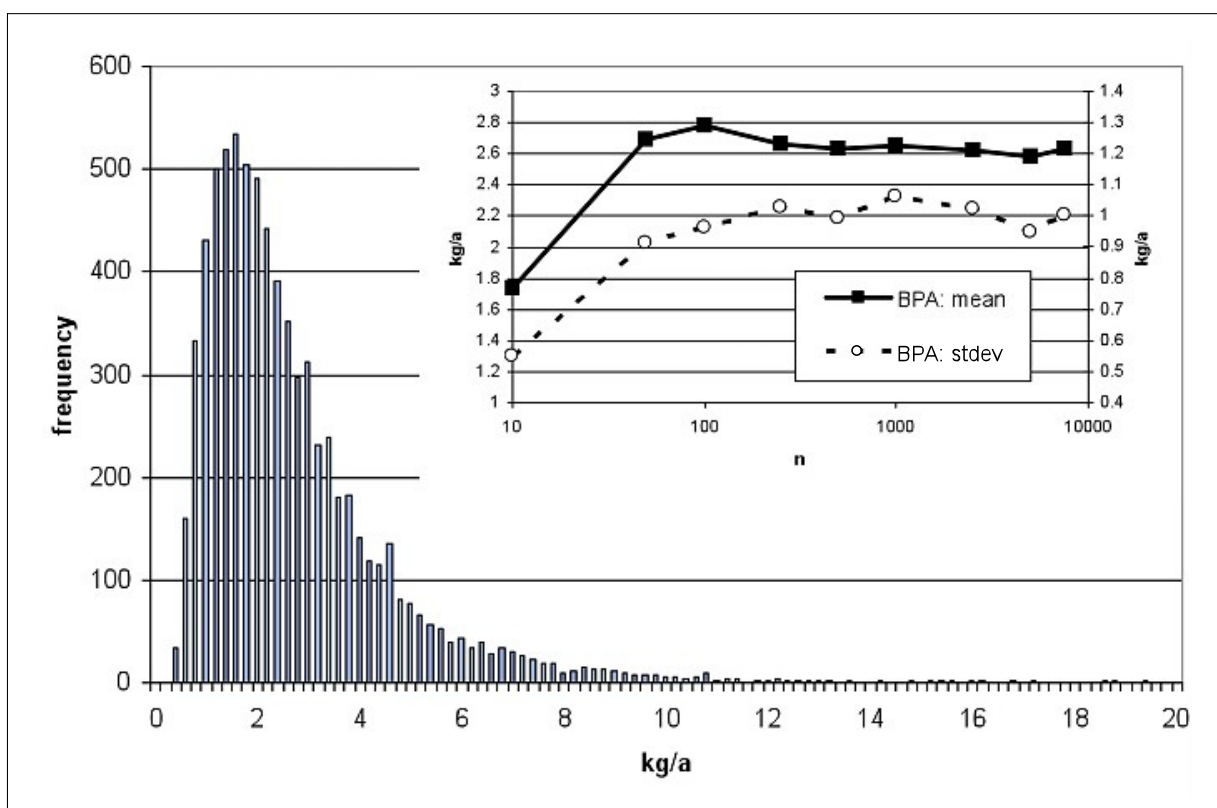

Fig. 3. Histogram showing the distribution of the mass flow of Bisphenol $A$ in the receiving water The inset shows the convergence of the distribution's mean value and standard deviation while increasing the number of runs.

surface waters a so-called estradiol equivalent concentration (EEQ) can be calculated using estradiol equivalence factors $(E E F$ $=E C_{50}($ Estradiol $) / E C_{50}\left(\right.$ substance $\left.\left._{i}\right)\right)$. $^{[13]}$ $\mathrm{EC}_{50}$ values of endocrine disruption exist for different endpoints, in its current state, the model calculates EEQs for MCF-7 cell proliferation (EEQ1), YES assay (EEQ2), ER-CALUX (EEQ3), and Vitellogenin synthesis (EEQ4). Since not all $\mathrm{EC}_{50}$ values are known for each substance and each endpoint, the individual EEQs are not readily comparable and should be regarded as indicators. $\mathrm{EC}_{50}$ data on the different endpoints was taken from literature. ${ }^{[13,14]}$

\section{Sensitivity and Uncertainty Analyses}

The modelled concentration of a substance depends on roughly 50 parameters (emission data, substance data, geographical data, and hydrological data). Sensitivity analyses were performed to assess the level of influence of every single parameter on the calculated result. Sensitivity varies with the substance properties: NP concentrations are highly sensitive to the degradation and formation constants of the precursor substances, whereas the most sensitive parameters for i.e. the concentration of the steroid hormones are the respective emissions.

To assess the model's uncertainty with respect to the calculated mass flows we performed uncertainty analyses for different substances. For these analyses we made assumptions for the shape of the distribution of every input parameter and subsequently ran simulations with parameter values randomly picked from these distributions. From the resulting distribution of the surface water concentrations we deduce the overall error. Fig. 3 shows the resulting distribution of mass flows of bisphenol A in the receiving water downstream of an STP.

\section{Scenarios Calculated}

Two scenarios have been calculated for the Glattal/Greifensee: in 2004 and 2007 with reduced NPnEO emissions due to new legislation as of August 2006. NPnEO-based detergents are only to be used in closed systems and are not allowed in wastewater streams. In this scenario the emissions are reduced to $1 \%$ of the 2004 emissions to account for any residual amounts of these compounds still used in 'normal' applications.

To assess the effect of different modes of operation for a single STP, two additional scenarios were set up for STP Egg: increased sludge retention time and adding an ozonation treatment step.

\section{Results}

\section{Comparison of Model Results with Measured Data}

Estimated mass flows and expected concentrations for surface waters for the various chemicals were compared to measured values from the same region. Comparisons were made for the 2004 emission scenario.

The course of nonylphenol concentrations as modelled and measured in the river Glatt downstream of Lake Greifencampaign was carried out in 2003 (June, August, and October by Voutsa et al. $\left.{ }^{[15]}\right)$, before the application ban of the parent substance NPnEO. The modelled concentrations are within the predicted uncertainty see is shown in Fig. 4. The measurement 


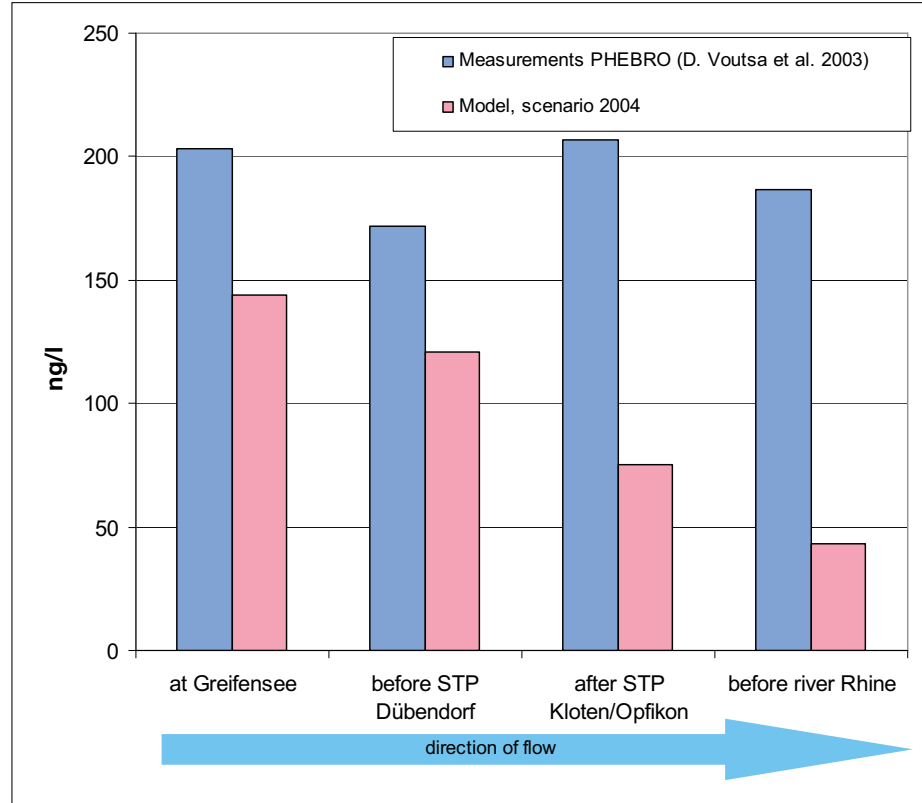

Fig. 4. Measured and modelled concentrations of nonylphenol in the river Glatt

of the model for this substance which is roughly one order of magnitude. Bearing the results of the sensitivity analyses in mind, the pronounced decrease of concentrations towards the river Rhine might be due to an underestimation of the parameters for the formation constants in the $\mathrm{NPnEO} \rightarrow \ldots \rightarrow \mathrm{NP}$ degradation formalism. All these parameters were shown to be important by the NP sensitivity analysis.

The Table summarizes concentration measurements in surface water bodies in the Glattal/Greifensee region. The year of measurement is given in parentheses. For the modelled concentrations the year whose emissions data were used is stated. The EEQs cannot be ascribed to a specific year since these are calculated from the individual substance concentrations.

In general, the model predicts the measured environmental concentrations in surface waters at least within an order of magnitude of the measured values. For the steroid hormones and bisphenol $\mathrm{A}$ the model makes excellent forecasts; for atrazine and desethylatrazine the modelled average concentrations are slightly lower than the measured values. This is due to the emission spikes in the summer months, the only application period of atrazine, where- as the model emissions take the form of an average atrazine mass flow throughout the year.

For nonylphenol the model predicts concentrations that are in the range of the measured concentrations in 2003 , but the concentrations of the precursor substances are much higher (our emission scenario is still before the complete ban of NPEOs, August 2006). This must be due to incorrect values of fractions of formation, and moreover, the degradation constant of NP must have been overestimated.

\section{Overview of Modelled Results for the Glattal/Greifensee Region, Scenario 2004}

Having validated the calculated concentration values for surface waters within the anticipated errors for the individual substances, we applied the proposed system of estradiol equivalence calculation based on the substance concentrations and the respective estradiol equivalence factors.

Visualization of the calculated EEQs helps to pin-point sections of surface waters with potentially high concentrations of endocrine-disrupting compounds. The modelling shows (Fig. 5), that high concentrations of endocrine-disrupting compounds can occur downstream of STPs with a low dilution ratio or at STPs receiving wastewaters from regions with high emissions.

Two examples for local hot-spots in the region have been identified: The brook $\mathrm{Aa}$ downstream of STP Egg/Oetwil and the river Glatt downstream of STP Dübendorf. For the small brook Aa downstream of STP Egg/Oetwil which treats mainly mu-

Table. Comparison of measured and modelled concentration in the river Glatt.

\begin{tabular}{|c|c|c|c|c|c|c|}
\hline \multirow[t]{2}{*}{ Parameter } & \multirow[t]{2}{*}{ Location $^{a}$} & \multirow[t]{2}{*}{ ref. } & \multicolumn{2}{|c|}{ measurement } & \multicolumn{2}{|c|}{ modelling $^{b}$} \\
\hline & & & $\mathrm{ng} / \mathrm{l}$ & year & $\mathrm{ng} / \mathrm{l}$ & scenario \\
\hline \multirow[t]{2}{*}{ EEQ (YES) } & Glatt d/s of STP Dübendorf & [16] & $1.0 \pm 0.4$ & 2003 & \multirow[t]{2}{*}{2.6} & \\
\hline & Glatt $d / s$ of former STP Glatt & [17] & $<\mathrm{LOQ}^{\mathrm{c}} \ldots 0.3$ & 1999 & & \\
\hline $\mathrm{E} 1$ & Glatt $d / s$ of former STP Glatt & {$[17]$} & $<\mathrm{LOQ} \ldots 1.6$ & 1999 & 0.088 & 2005 \\
\hline E2 & Glatt $d / s$ of former STP Glatt & [17] & $<\mathrm{LOQ}$ & 1999 & 0.016 & 2005 \\
\hline E3 & Glatt $d / s$ of former STP Glatt & [17] & $<$ LOQ ...1.4 & 1999 & 0.21 & 2005 \\
\hline EE2 & Glatt $d / s$ of former STP Glatt & [17] & $<\mathrm{LOQ}$ & 1999 & 0.019 & 2005 \\
\hline \multirow[t]{2}{*}{ Atrazine } & Glatt d/s of STP Dübendorf & [18] & 40 & 03-09/2003 & 8 & 2004 \\
\hline & Glatt $d / s$ of STP Rheinsfelden & [18] & 60 & 03-09/2003 & 10 & 2004 \\
\hline \multirow[t]{2}{*}{ Desethylatrazine } & Glatt d/s of STP Dübendorf & [18] & 35 & 03-09/2003 & 11 & 2004 \\
\hline & Glatt $d / s$ of STP Rheinsfelden & [18] & 25 & 03-09/2003 & 2.5 & 2004 \\
\hline \multirow[t]{2}{*}{ Bisphenol A } & Glatt d/s of STP Opfikon-Kloten & [15] & 35 & 2004 & 37 & 1999 \\
\hline & Glatt $d / s$ of STP Rheinsfelden & [15] & 50 & 2004 & 28 & 1999 \\
\hline \multirow[t]{2}{*}{ Nonylphenol } & Glatt d/s of STP Opfikon-Kloten & [15] & 180 & 2004 & 76 & 2004 \\
\hline & Glatt $d / s$ of STP Rheinsfelden & {$[15]$} & 160 & 2004 & 44 & 2004 \\
\hline
\end{tabular}

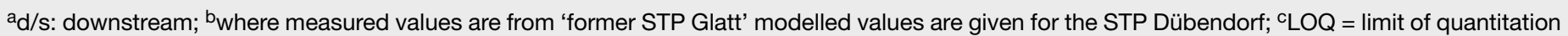
in ref. [16]: E1: $0.7 \ldots 1.0 \mathrm{ng} / \mathrm{l}$, E2: $0.5 \ldots 0.9 \mathrm{ng} / \mathrm{l}$, E3: $1 \ldots 1.5 \mathrm{ng} / \mathrm{l}$, EE2: $0.7 \ldots 1 \mathrm{ng} / \mathrm{l}$ and for NP $90 \mathrm{ng} / \mathrm{l}$ 


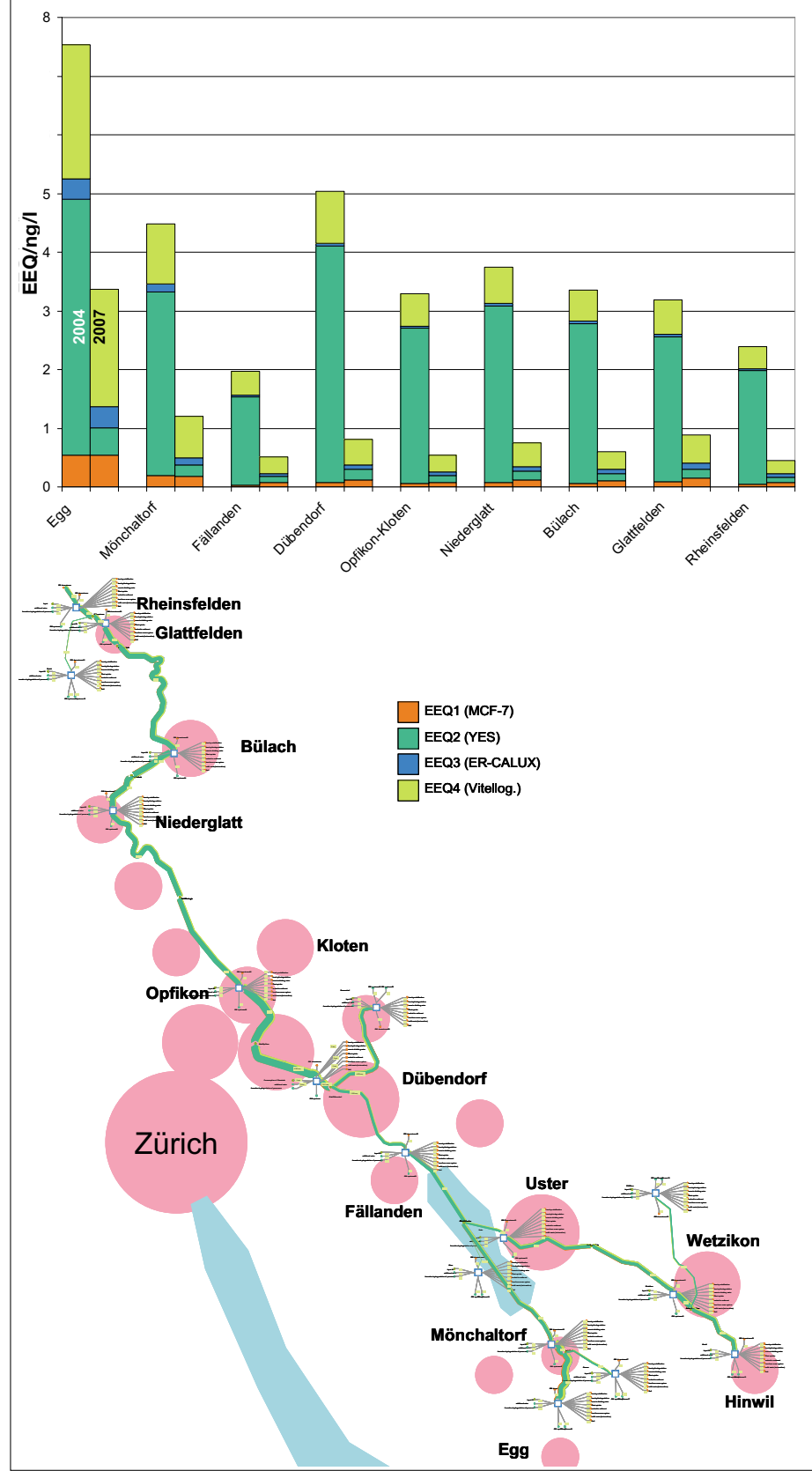

Fig. 5. EEQs in receiving waters of the Glatt/Greifensee catchment area modelled for 2004 and 2007 emission scenarios.

nicipal wastewater, the main contribution to the EEQ are the steroid hormones. However, the STP Dübendorf receives a large portion of industrial wastewater containing NPnEO which leads to corresponding high EEQ values in the YES assay activity (EEQ2) from NPnEO.

\section{Comparison of Emission Scenarios for NPnEO 2004 and 2007}

Due to the ban of NPnEO we assumed drastically reduced usage and a corresponding reduction in emissions (99\% reduction), particularly in catchment areas with high industrial activities. The reduced emissions of NPnEO in the Dübendorf region result in large reductions in the concentrations of NPnEO metabolites and therefore have a pronounced effect on the

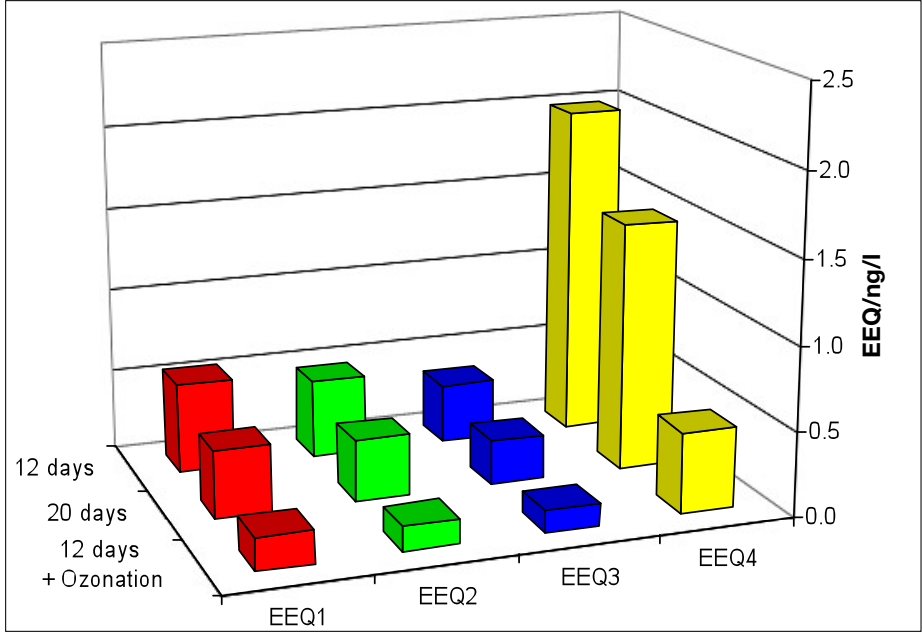

Fig. 6. Calculated EEQs in the receiving water downstream of STP Egg (brook Aa) when applying different treatment options for the 2007 emission scenario: sludge age of 12 and 20 days and an additional ozonation step. EEQ1: MCF-7, EEQ2: YES, EEQ3: ER-CALUX, EEQ4: Vitellogenin.

tribute substantially to the overall EEQ. The estradiol equivalent concentrations of BPA, UV filters, and flame retardants are at least two orders of magnitude below the main contributors' concentration value. This might change in situations where higher loads of single compounds are discharged (e.g. BPA in effluent of an industrial STP).

In parallel with the decrease in surface water concentrations, the concentrations in other environmental compartments are also expected to decrease. The estimated concentration of NP in freshly formed sediments is reduced by a factor of 100 between 2004 and 2007 (data not shown).

\section{Modelling Risk Reduction Measures for the STP Egg}

For the STP Egg in the Glattal/Greifensee region we calculated two additional scenarios for different treatment alternatives for the 2007 scenario emissions: Increase of sludge retention time from 12 days to 20 days and the addition of an ozonation treatment step. The rainwater bypass was set to an average of $3 \%$. For all three cases we compare the endocrine potential in the receiving water, not in the STP effluent.

In general, the pollutant concentration decreases as sludge retention time is increased or the ozonation step is implemented.

Fig. 6 shows that increasing sludge retention time can reduce the EEQ in the receiving water. For the four endpoints (EEQ1 to EEQ4) the endocrine potential is decreased by $30 \%$. Adding the ozonation step reduces all EEQs by at least $70 \%$ (EEQ2) compared to the $12 \mathrm{~d}$ scenario. It was assumed that NPnEO and its degrada- 
tion products are reduced by $80 \%$, while NP is reduced by $99 \%$.

Compared to the good elimination in the STP (e.g. for E2 the removal rates are: $93 \%(12 \mathrm{~d}), 96 \%(20 \mathrm{~d})$, and $99.8 \%$ (ozonation) respectively), the resulting EEQs in the receiving water are relatively high. This is due to the residual amount of pollutants that do not pass the STP but are discharged directly into the receiving water, either by rainwater bypass or by product leaching and surface run-off (e.g. bisphenol A) and the amount of pollutants already present in the receiving water.

\section{Conclusions}

The model calculations have shown that it is possible to estimate environmental concentrations and the corresponding ecotoxicity for various substances simultaneously based on a very limited data set. The model allows the prediction not only of environmental concentration on a yearly average basis but also the generation of predictions for specific environmental scenarios such as improvement of STP, rain events etc.

The substances modelled in this project have been thoroughly studied by various research groups and therefore were ideal for the validation of the model. Since the substances used represent a wide range of physical-chemical properties and emission pathways the model is ready to predict the movement and fate of other chemicals such as pharmaceuticals, biocides, corrosion inhibitors etc.

The model can easily be adapted to new geographical areas and a model for Switzerland is envisaged, which would include all major STP and surface waters of Switzerland.

Since the model has an integrated compound database new (emerging) chemicals can be introduced as they are studied by the environmental authorities or research groups. This provides an overview of the environmental contamination of the surface waters in Switzerland. The model can serve as an important tool for the management of the risk posed by emissions of chemicals. The models allows risk management options such as local vs. central wastewater treatment, restriction of chemicals or organizational changes in the management of wastewater to be assessed.

\section{General conclusions}

EEQs vary from endpoint to endpoint, which is especially critical for NPnEO and its degradation products which exhibit high activity in the YES assay. However, this result can be used to demonstrate the effect of risk reduction measures (i.e. the restricted use of NPnEO). With respect to the results of the YES assay the endocrine potential in the river Glatt after the STP Dübendorf has been reduced between 2004 and 2007 by a factor of 25 due to the restrictions in the use of NPnEO.

\section{Glattal/Greifensee Region}

The endocrine disruption potential in the river Glatt varies from low (outflow of Lake Greifensee) to high (downstream of STP Dübendorf). Compared to the average concentration in the river Glatt at Glattfelden (before flowing into river Rhine) the highest local concentrations in the catchment area are up to about a factor of eight higher. These so called hot spots are due to STPs discharging into small receiving waters (STP Egg, STP Bassersdorf). Further reasons for locally higher concentrations are high industrial emissions (STP Dübendorf) and low removal efficiency (STP Egg).

Although the estimated local concentrations are high, they are rather low when compared to published concentrations from other countries such as Great Britain or the USA. Williams et al. ${ }^{[19]}$ measured estradiol concentrations of up to $4.3 \mathrm{ng} / \mathrm{l}$ and estrone concentrations of up to 12.2 $\mathrm{ng} / \mathrm{l}$ in rivers downstream of STPs, which are at least a factor of six higher than our modelled yearly averages.

\section{Relevant Endocrine-disrupting Chemicals}

From the 20 substances modelled in this project only a few substantially contribute to the overall endocrine-disruption potential. For three of the endpoints used, the steroid hormones dominate the endocrine potential. Only the application of the YES assay predicts a dominant endocrine potential for the degradation products of NPnEO in 2004, which decreases significantly in the year 2007.

The contribution of substances such as bisphenol $\mathrm{A}$ and the various UV filters to the overall endocrine potential is small. However, it has to be considered that the endocrine potential for all endpoints is not known for all the substances entering surface waters. Near major emission sources (e.g. wastewater of a specific industry) these chemicals may become relevant.

\section{Attempt to Assess the Situation for the Glattal/Greifensee Region}

Based on the modelling results the following conclusions can be drawn for Switzerland:

- The overall endocrine potential in surface water depends mainly on the efficiency of the corresponding STP and the dilution ratio of the treated effluent in the surface water.

- Most areas of Switzerland are less densely populated compared to the
Glattal/Greifensee region or are located in the catchment area of large surface water systems. Therefore it can be concluded that in general a low endocrine potential can be expected for a large part of Switzerland.

- Catchment areas with large populations and STPs discharging to small surface waters (hot spots) can lead to endocrine potentials which are in the order of magnitude of the $\mathrm{EC}_{50}$ values for estradiol for the most sensitive endpoint used (e.g. MCF-7). The environmental significance of the individual endpoints is still under discussion.

- In state-of-the-art Swiss STPs most of the steroid hormones passing through the plant are eliminated (sludge age $>10$ days). In order to further reduce the endocrine potential as well as other micropollutants in STPs additional treatment steps are being assessed by the federal government (ozonation, activated carbon).

- In addition organizational measures such as the combined treatment of wastewater from different small and ineffective STPs in larger and more effective plants or the direction of the treated wastewater to larger surface waters are possible.

Received: March 22, 2008

[1] R. P. Schwarzenbach, B. I. Escher, K. Fenner, T. B. Hofstetter, C. A. Johnson, U. von Gunten, B. Wehrli, Science 2006 , 313,1072 .

[2] EUSES 2.0, European Commission, National Institute of Public Health and the Environment (RIVM), Bilthoven, Netherlands, 2004.

[3] T. Feijtel, G. Boeije, M. Matthies, A. Young, G. Morris, C. Gandolfi, B. Hansen, K. Fox, M. Holt, V. Koch, R. Schroder, G. Cassani, D. Schowanek, J. Rosenblom, H. Niessen, Chemosphere 1997, 34, 2351.

[4] A. B. A. Boxall, Environ. Sci. Technol. 2004, 38, 368A.

[5] T. M. Cahill, I. Cousins, D. Mackay, Environ. Toxicol. Chem. 2003, 22, 483.

[6] K. Fenner, M. Scheringer, K. Hungerbühler, Environ. Sci. Technol. 2000, 34, 3809.

[7] M. Schluep, R. Gälli, Swiss National Science Foundation NRP50 project 03, Final Report, 2004.

[8] Estimation Programs Interface Suite ${ }^{\mathrm{TM}}$ for Microsoft ${ }^{\circledR}$ Windows, v3.20. United States Environmental Protection Agency, USA, 2000.

[9] U.Schenker, M. MacLeod, M. Scheringer, K. Hungerbühler, Environ. Sci. Technol. 2005, 39, 8434.

[10] 'European Union Risk Assessment Report, 4,4'-isopropylidenediphenol (bisphenol A)', Volume 37, Editors: S.J. Munn, R. Allanou, K. Aschberger, F. Berthault, J. de Bruijn, C. Musset, S. 
O'Connor, S. Pakalin, G. Pellegrini, S. Scheer, S. Vegro, Luxembourg, Office for Official Publications of the European Communities, 2003.

[11] C. Leu, H. Singer, S. R. Müller, R. P. Schwarzenbach, C. Stamm, J. Environ. Qual. 2005, 34, 1873.

[12] A. Buser, L. Morf, Swiss National Science Foundation NRP50 project 29 (FABRO), personal communication, 2006.

[13] B. V. Rutishauser, M. Pesonen, B. I. Escher, G. E. Ackermann, H.-R. Aerni, M. J.-F. Suter, R.I.L. Eggen, Environ. Toxicol. Chem. 2004, 23, 857.

[14] a) S. Jobling, J. P. Sumpter, Aquat. Toxicol. 1993, 27, 361; b) J. P. Sumpter, A. C. Johnson, Environ. Sci. Technol. 2005, 39, 4321; c) J. Legler, A. Jonas, J. Lahr, A. D. Vethaak, A. Brouwer, A. J. Murk, Environ. Toxicol. Chem. 2002, 21, 473; d) A. M. Soto, H. Justicia, J.W. Wray, C. Sonnenschein, Environ. Health Perspect. 1991, 92, 167; e) A. M. Soto, C. Sonnenschein, Endocrinology 2005, 146, 2127; f) M. Schlumpf, B. Cotton, M. Conscience, V. Haller, B. Steinmann, W. Lichtensteiger, Environ. Health Perspect. 2001, 109, 239; g) W. Körner, W. Schuller, H. Hagemaier, V. Hanf,
Research Report University Tübingen, PUG U 95 004, 1999; h) K. L. Thorpe, R. I. Cummings, T. H. Hutchinson, M. Scholze, G. Brighty, J. P. Sumpter, C. R. Tyler, Environ. Sci. Technol. 2003, 37, 1142.

[15] D. Voutsa, P. C. Hartmann, C. Schaffner, W. Giger, Environ. Sci. Pollut. Res. 2006 , 13,333 .

[16] E. L. M. Vermeirssen, R. Burki, C. Joris, A. Peter, H. Segner, M. J.-F. Suter, P. Burkhardt-Holm, Environ. Toxicol. Chem. 2005, 24, 2226.

[17] H.-R. Aerni, B. Kobler, B. V. Rutishauser, F. E. Wettstein, R. Fischer, W. Giger, A. Hungerbühler, M. D. Marazuela, A. Peter, R Schönenberger, A. C. Vögeli, M. J.-F. Suter, R. I. L. Eggen, Anal. Bioanal. Chem. 2004, 378, 688 .

[18] O. Jäggi, C. Balsiger, H. Pfister, S. Huber, R. Schönhauser, P. Niederhauser, W. Meier, 'Pestizide in Oberflächengewässern', Amt für Abfall, Wasser, Energie und Luft, Abteilung Gewässerschutz, Zürich, 2003.

[19] R. J. Williams, A. C. Johnson, J. J. L. Smith, R. Kanda, Environ. Sci. Technol. 2003, 37, 1744 . 